\title{
Thành lập bản đồ phân vùng nguy cơ trượt lở đất Thành phố Đà Lạt bằng phương pháp phân tích thứ bậc và hệ thông tin địa lý
}

\section{GIS based landslide hazard mapping with application of analytical hierarchy process for Da Lat City}

\author{
Lê Ngọc Thanh ${ }^{1 *}$, Nguyễn Quang Dũng ${ }^{1}$, Nguyễn Siêu Nhân ${ }^{1}$, Nguyễn Phi Hùng ${ }^{1}$, \\ Lưu Hải Tùng $^{1}$ \\ ${ }^{1}$ Viện Địa lý Tài nguyên Thành phố Hồ Chí Minh, Việt Nam \\ *Tác giả liên hệ, Email: lnthanh@ @cmig.vast.vn
}

THÔNG TIN

DOI: $10.46223 /$ HCMCOUJS. tech.vi.16.1.1229.2021

Ngày nhận: 21/10/2020

Ngày nhận lại: 23/10/2020

Duyệt đăng: 28/10/2020

\section{Tù̀ khóa:}

phương pháp phân tích thứ bậc AHP; trượt lở đất; Thành phố Đà Lạt

\section{TÓM TẮT}

Bản đồ phân vùng nguy cơ trượt lở đất Thành phố Đà Lạt đã được thành lập bằng phương pháp phân tích thứ bậc $\mathrm{AHP}$ và hệ thông tin địa lý. Mười ba yếu tố/nguyên nhân đã được lựa chọn sử dụng bao gồm độ dốc sườn, địa mạo, lưu vực sông - mật độ sông suối, thạch học - vỏ phong hóa, thổ nhưỡng, cấu trúc địa động lực, đới ảnh hưởng động lực các đứt gãy chính, gia tốc nền, địa chất thủy văn, lượng mưa trung bình năm, hiện trạng sử dụng đất, mật độ xây dựng và hệ thống giao thông. Phân vùng nguy cơ trượt lở đất được kiểm chứng bằng cách so sánh với hiện trạng 214 địa điểm trượt lở đất đã phát hiện từ điều tra, khảo sát thực tế. Kết quả cho thấy $94.8 \%$ vị trí địa điểm trượt lở đất phát sinh trong các vùng nguy cơ từ trung bình đến rất cao. Các vùng có nguy cơ trượt lở đất từ rất thấp, thấp, trung bình, cao đến rất cao lần lượt chiếm $21.76 \% ; 36.14 \% ; 21.15 \% ; 15.91 \%$ và $5.04 \%$ diện tích khu vực nghiên cứu. Độ dốc sườn $>25^{\circ}$, lượng mưa trung bình năm từ $1800-1900 \mathrm{~mm}$, mật độ xây dựng $>80 \%$ và hệ thống giao thông với bước đệm $20 \mathrm{~m}$ được coi là các yếu tố/nguyên nhân chủ yếu trong phát sinh trượt lở đất trên địa bàn Thành phố Đà Lạt. Kết quả nghiên cứu là tài liệu khoa học và thực tiễn giúp các nhà quy hoạch và quản lý địa phương sử dụng hợp lý lãnh thổ thành phố có tính đến điều kiện trượt lở đất trong quy hoạch tổng thể phát triển kinh tế - xã hội.

ABSTRACT
Landslide hazard mapping for Da Lat City has been
generated by Analytical Hierarchy Process AHP and GIS.
Thirteen causual factors were selected, including slope,
geomorphology, river catchment density, lithology-weathering
zone, soil, geodynamic structure, dynamic impact zone of main
faults, peak ground acceleration, hydrogeology, annual average
rainfall, land use, construction density, and transport system.
Landslide hazard zoning was verified by comparing it with the




\section{Keywords:}

analytical hierarchy process AHP; Da Lat City; landslide current 214 landslide locations detected from the actual investigation and survey. Results showed that $94.8 \%$ of landslide locations occurred in moderate to very high hazard areas. Areas with deficient, low, medium, high, to very high landslide hazard accounted respectively for $21.76 \% ; 36.14 \% ; 21.15 \% ; 15.91 \%$, and $5.04 \%$ of the study area. Slope $>25^{\circ}$, annual average rainfall from 1800-1900mm, construction density > 80\%, and traffic system with a buffer of $20 \mathrm{~m}$ were considered as the main causual factors to landslide occurrence in Da Lat City. Research results are a scientific and practical basis for local planners and managers to use suitably the city territory, considering the landslide condition in the socio-economic development master plan.

\section{Giới thiệu}

Trượt lở đất là tai biến địa chất phổ biến thường xảy ra trong vùng đồi núi, không chỉ làm thiệt mạng mà còn gây tổn thất tài sản. Điều đó thúc đẩy nhiều công trình công bố theo hướng này với các phương pháp nghiên cứu khác nhau. Hiện nay, trong các nghiên cứu về trượt lở đất có hai nhóm phương pháp là định tính và định lượng (Adnan \& Tolga, 2013; Dang et al., 2019; X. H. Nguyen et al., 2019; Le et al., 2012, 2020). Phương pháp định tính chủ yếu dựa vào kiến thức và kinh nghiệm của các chuyên gia. Phương pháp định lượng có các phương pháp thống kê như Tỷ lệ tần suất $(\mathrm{FR})$, Trọng lượng bằng chứng (WOE), Hồi quy logistic (LR) và Phân tích thứ bậc (AHP). AHP là một phương pháp phân tích đa tiêu chí, một công cụ hiệu quả cho việc ra quyết định phức tạp trong nhiều lĩnh vực và đã được sử dụng rộng rãi trong việc lựa chọn các yếu tố/thành phần tác động đến trượt lở đất, là dữ liệu đầu vào để thành lập bản đồ phân vùng nguy cơ trượt lở đất trong một khu vực nghiên cứu (Ahmad, 2018; Rahim, Ali, \& Aslam, 2018; Peng, Shieh, \& Fan, 2012).

Ở Việt Nam, trong khu vực Tây Nguyên đã thực hiện một số nghiên cứu về tai biến địa chất như X. H. Nguyen và cộng sự (2019) với đề tài "Nghiên cứu một số dạng tai biến địa chất điển hình phục vụ kinh tế - xã hội Tây Nguyên" nhằm đánh giá hiện trạng bốn dạng tai biến địa chất điển hình là nứt sụt đất, trượt lở đất, lũ quét - lũ bùn đá và xói lở bờ sông; Phan và cộng sự (2016) trong đề tài "Nghiên cứu hoạt động địa động lực hiện đại khu vực Tây Nguyên phục vụ dự báo các dạng tai biên địa chất ở các vùng đập, hồ chứa và đề xuất các giải pháp phòng tránh" đã nghiên cứu làm sáng tỏ đặc điểm địa động lực hiện đại khu vực Tây Nguyên và ảnh hưởng của chúng tới đập và hồ chứa.

Tỉnh Lâm Đồng là nơi tai biến địa chất có khả năng xảy ra quy mô lớn với bốn dạng tai biến địa chất điển hình là nứt, sụt đất, trượt lở đất và lũ quét. Trong những năm 1993-1994, Pham, Do, và Nguyen (1994) đã tiến hành nghiên cứu kiến tạo, đứt gãy, trường ứng suất kiến tạo cho tỉnh Lâm Đồng, chỉ ra một số đứt gãy có biểu hiện hoạt động là nguyên nhân tiềm ẩn gây ra các dạng tai biến địa chất có nguồn gốc hỗn hợp như động đất, nứt đất, trượt lở đất, núi lửa, lũ bùn, phun tro, phun bùn, hạ lún, nâng vòm, thoát mất nước ngầm. Năm 2012 nhóm nghiên cứu (Le et al., 2012) đã hoàn thành đề tài "Nghiên cứu tai biến địa chất, những vùng có nguy cơ nứt đất, trượt lở đất, lũ quét, đề xuất các giải pháp phòng tránh giảm nhẹ thiệt hại trên địa bàn tỉnh Lâm Đồng." Năm 2020, Le và cộng sự (2020) tiếp tục thực hiện đề tài "Nghiên cứu các tai biến địa chất: nứt, sụt đất, trượt lở đất và đề xuất các biện pháp cảnh báo, ngăn ngừa và khắc phục trên địa bàn Thành phố Đà Lạt, tỉnh Lâm Đồng."

Trong đêm 25/04/2017 trên địa bàn Thành phố Đà Lạt đã xảy ra sự cố nứt đất - nhà và đường khu vực đường Nguyễn Văn Trỗi - Phan Đình Phùng, Phường 02, gây hoang mang dư 
luận và thiệt hại nhà cửa, đe dọa tính mạng của người dân trong khu vực $(\mathrm{N}$. P. Nguyen, Kanno, \& Bui, 2017). Dang và cộng sự (2019) đã xây dựng bản đồ độ nhạy cảm trượt lở đất Thành phố Đà Lạt bằng phương pháp FR dựa trên 8 yếu tố/nguyên nhân và 72 địa điểm trượt lở đất thu thập. Kết quả cho thấy $6.27 \%$ diện tích nằm trong vùng nhạy cảm rất thấp; $21.03 \%$ - vùng nhạy cảm thấp; $27.09 \%$ - vùng nhạy cảm trung bình; $27.41 \%$ - vùng nhạy cảm cao; và $18.21 \%$ - vùng nhạy cảm rất cao. Bài báo này sử dụng phương pháp AHP trong môi trường GIS nhằm xây dựng bản đồ nguy cơ trượt lở đất Thành phố Đà Lạt, góp phần phòng tránh hiệu quả loại hình tai biến địa chất này.

\section{Phương pháp và dữ liệu nghiên cứu}

\subsection{Khu vục nghiên cúu}

Lâm Đồng một tỉnh miền núi phía Nam Tây Nguyên với hai thành phố và 10 huyện. Thành phố Đà Lạt nằm ở phía Bắc tỉnh Lâm Đồng có tọa độ địa lý: từ $108^{0} 19^{\prime} 23$ " đến $108^{0} 36^{\prime} 27^{\prime}$ " kinh độ Đông và từ $11^{0} 48^{\prime} 36^{\prime \prime}$ đến $12^{0} 01^{\prime} 07^{\prime \prime}$ vĩ độ Bắc. Thành phố Đà Lạt tọa lạc trên cao nguyên Lâm Viên, ở độ cao $1500 \mathrm{~m}$ so với mặt nước biển, với diện tích tự nhiên khá nhỏ chỉ gần $40 \mathrm{~km}^{2}$ (Hình 1).

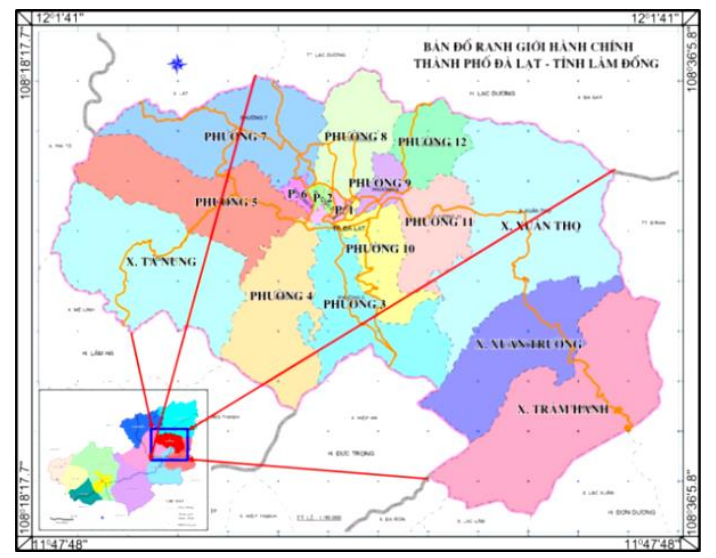

Hình 1. Bản đồ vị trí khu vực nghiên cứu (Thành phố Đà Lạt)

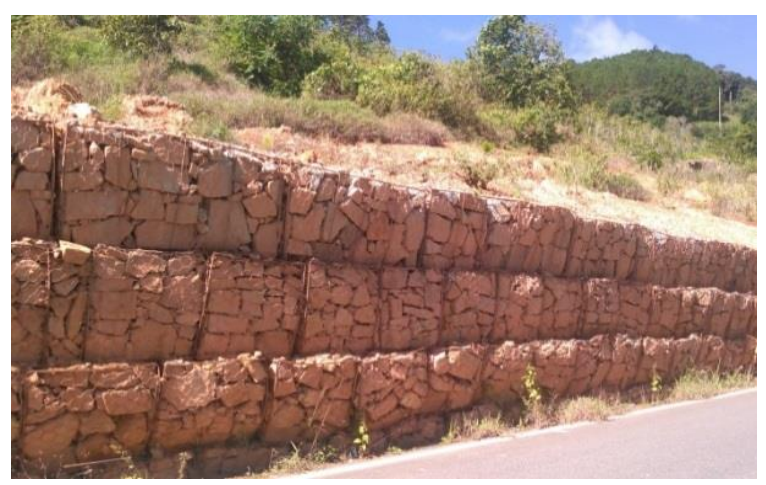

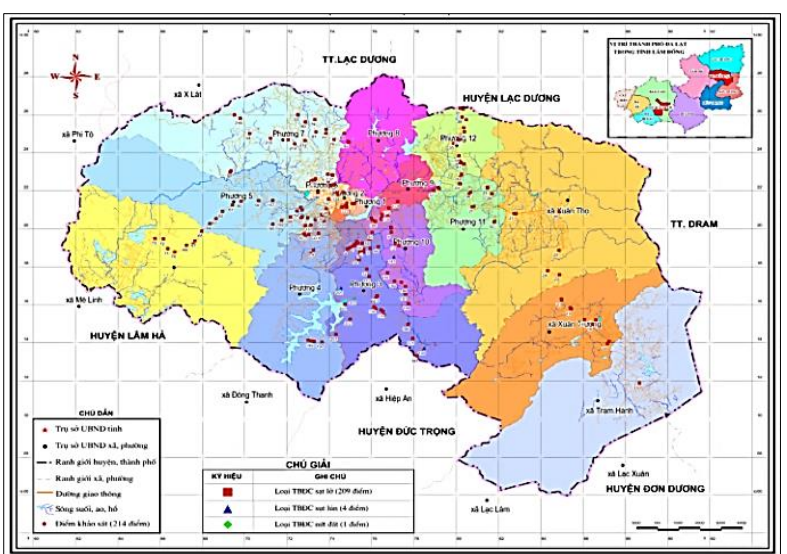

Hình 2. Bản đồ vị trí các địa điểm trượt lở đất

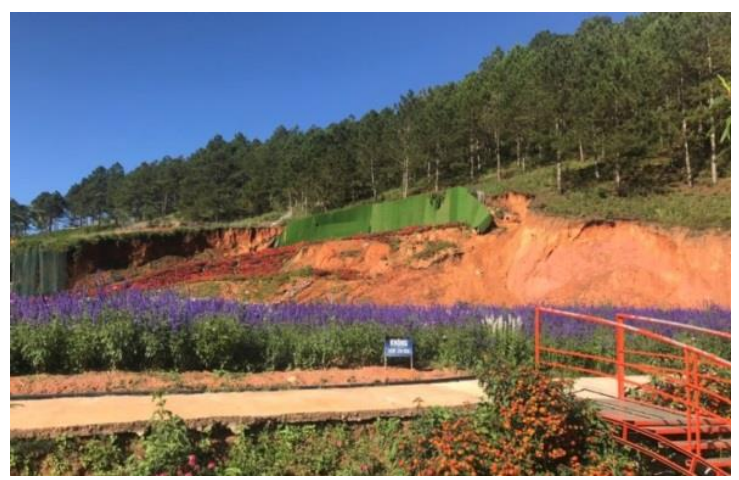

Hình 3. Ảnh chụp trượt lở đất trong khu vực nghiên cứu

\subsection{Phương pháp nghiên cúu}

\subsubsection{Phuơng pháp AHP}

Phương pháp phân tích thứ bậc AHP được Saaty (1980) đề xuất và sử dụng vào việc ra các quyết định khác nhau. Trong đó trong ma trận so sánh trị số của mỗi yếu tố thay đổi trong khoảng từ 01 đến 09 . Các yếu tố được sắp xếp theo thứ bậc trong ma trận và kỹ thuật Đánh giá 
yếu tố ưu tiên (PFRV) được sử dụng để gán trị số cho các yếu tố trên cơ sở mức độ quan trọng của chúng so với các yếu tố khác. Trị số được gán cho các yếu tố dựa trên kiến thức chuyên môn, tài liệu, quan sát và kinh nghiệm.

Giá trị trung bình của các yếu tố được sắp xếp theo thứ bậc được sử dụng để tính trọng số và giá trị riêng (eigenvalue) cùng với tỉ số nhất quán $(\mathrm{CR})$. Tính nhất quán của ma trận so sánh được kiểm tra thông qua $\mathrm{CR}$.

$$
C R=C I / R I
$$

trong đó, $\mathrm{CI}$ là chỉ số nhất quán, RI - chỉ số nhất quán ngẫu nhiên. Nói chung, $\mathrm{CR} \leq 0.1$ được chấp nhận, khi $\mathrm{CR}>0.1$ cho thấy sự không nhất quán cần phải so sánh lại. Phần mềm Expert Choice v11 đã được sử dụng để phân tích AHP trong nghiên cứu này.

\subsubsection{Tổ hợp tuyến tính có trọng số}

Tổ hợp tuyến tính có trọng số phụ thuộc vào quy trình kết hợp các bản đồ thành phần (các lớp). Đây là bước cuối cùng trong việc xây dựng bản đồ phân vùng nguy cơ trượt lở đất, trong đó tất cả các lớp được kết hợp bằng cách sử dụng kỹ thuật chồng chập có trọng số trong phần mềm ArcGIS. Tất cả các lớp đã được phân loại lại theo tỷ lệ cụ thể. Trọng số của các yếu tố được kết hợp với nhau để thu được chỉ số nguy cơ trượt lở đất theo công thức:

$$
L S I=\sum_{j=i}^{n} W_{j} \cdot w_{i j}
$$

trong đó chỉ số nhạy cảm LSI, giá trị trọng lượng $\mathrm{W}_{\mathrm{j}}$ cho tham số j, giá trị xếp hạng $\mathrm{w}_{\mathrm{ij}}$ hoặc giá trị trọng lượng của loại $\mathrm{I}$ trong tham số $\mathrm{j}$ và $\mathrm{n}$ của các lớp.

Trọng số của các yếu tố được xác định bằng phương pháp phân tích thứ bậc AHP, được sử dụng để thành lập bản đồ phân vùng nguy cơ trượt lở đất bằng công thức (2). Việc phân loại các giá trị pixel thực hiện bằng thuật toán Natural breaks trong phần mềm ArcGIS.

\subsubsection{Bản đồ hiện trang các địa điểm truợt lở đất}

Đã tiến hành khảo sát các khu vực có dấu hiệu, thông tin về trượt lở đất nhằm thu thập thông tin hiện trạng của chúng trong ba đợt: tháng 10,11/2018; tháng 06/2019 và tháng 06/2020. Trên cơ sở kết quả điều tra và khảo sát thực tế, đã phát hiện 214 địa điểm trượt lở đất trên địa bàn Thành phố Đà Lạt; thể hiện trên bản đồ hiện trạng trượt lở đất ở dạng bản đồ số bao gồm các thuộc tính như vị trí, đặc điểm phân bố, nguyên nhân, quy mô, ... có khả năng truy cập, bổ sung và cập nhật thông tin mới trong môi trường GIS (Hình 2). Bản đồ hiện trạng trượt lở đất cho phép hình dung phân bố không gian của chúng trong khu vực nghiên cứu, và là tài liệu thực tế kiểm chứng độ tin cậy của bản đồ phân vùng nguy cơ trượt lở đất.

\subsubsection{Phân tích thứ bậc AHP}

Kết quả phân tích $\mathrm{AHP}$ cho thấy $\mathrm{CR}$ tính toán từ ma trận so sánh cho 13 yếu tố bằng 0.09. Giá trị này chứng tỏ ma trận các yếu tố là chấp nhận được. Trọng số của các yếu tố/nguyên nhân $(\mathrm{Wj})$ và trị số yếu tố (wij) trình bày trong Bảng 1 .

\section{Bảng 1}

Ma trận so sánh cặp của các yếu tố 


\begin{tabular}{|c|c|c|c|c|c|c|c|c|c|c|c|c|c|c|c|}
\hline Yếu tố & $\begin{array}{c}\text { Độ } \\
\text { dốc } \\
\text { sườ } \\
\text { n }\end{array}$ & $\begin{array}{l}\text { Địa } \\
\text { mạo }\end{array}$ & $\begin{array}{c}\text { Lưu } \\
\text { vực } \\
\text { sông- } \\
\text { mật } \\
\text { dộ̣ } \\
\text { sông } \\
\text { suối }\end{array}$ & $\begin{array}{l}\text { Thạc } \\
\text { h } \\
\text { học- } \\
\text { vỏ } \\
\text { phon } \\
\text { g hóa }\end{array}$ & $\begin{array}{l}\text { Thổ } \\
\text { như } \\
\text { ơng }\end{array}$ & $\begin{array}{c}\text { Cấu } \\
\text { trúc } \\
\text { địa } \\
\text { độn } \\
\text { g } \\
\text { lực }\end{array}$ & $\begin{array}{c}\text { Đới } \\
\text { ảnh } \\
\text { hưởng } \\
\text { động } \\
\text { lực } \\
\text { các } \\
\text { đứt } \\
\text { gãy }\end{array}$ & $\begin{array}{c}\text { Gi } \\
\mathbf{a} \\
\text { tốc } \\
\text { nề } \\
\text { n } \\
\text { cự } \\
\mathbf{c} \\
\text { đạ } \\
\text { i }\end{array}$ & $\begin{array}{l}\text { Địa } \\
\text { chất } \\
\text { thủy } \\
\text { văn }\end{array}$ & $\begin{array}{c}\text { Lur } \\
\text { ọn } \\
\text { g } \\
\text { m } \\
\text { ura } \\
\text { nă } \\
\text { m }\end{array}$ & $\begin{array}{l}\text { Hiện } \\
\text { trạn } \\
\text { g sử } \\
\text { dụng } \\
\text { dất }\end{array}$ & $\begin{array}{c}\text { Mật } \\
\text { dộ } \\
\text { xây } \\
\text { dụ̣n } \\
\text { g }\end{array}$ & $\begin{array}{c}\text { Hệ } \\
\text { thống } \\
\text { giao } \\
\text { thông }\end{array}$ & $\begin{array}{c}\text { Trọng } \\
\text { số }\end{array}$ & $\begin{array}{l}\text { Hệf } \\
\text { số }\end{array}$ \\
\hline $\begin{array}{l}\text { Độ dốc } \\
\text { sườn }\end{array}$ & 1 & 3 & 7 & 2 & 6 & 8 & 8 & 4 & 8 & 2 & 6 & 2 & 2 & 0.190 & 8 \\
\hline $\begin{array}{l}\text { Địa } \\
\text { mạo }\end{array}$ & $1 / 3$ & 1 & 3 & 1 & 6 & 7 & 7 & 3 & 7 & 3 & 6 & 3 & 3 & 0.097 & 7 \\
\hline $\begin{array}{l}\text { Lưu } \\
\text { vực } \\
\text { sông- } \\
\text { mật độ } \\
\text { sông } \\
\text { suối }\end{array}$ & $1 / 7$ & $1 / 3$ & 1 & 2 & 2 & 6 & 6 & 3 & 5 & 5 & 2 & 5 & 5 & 0.041 & 6 \\
\hline $\begin{array}{l}\text { Thạch } \\
\text { học-vỏ } \\
\text { phong } \\
\text { hóa }\end{array}$ & $1 / 2$ & 1 & $1 / 2$ & 1 & 2 & 7 & 7 & 3 & 4 & 4 & 2 & 5 & 5 & 0.064 & 7 \\
\hline $\begin{array}{l}\text { Thổ } \\
\text { nhưỡng }\end{array}$ & $1 / 6$ & $1 / 6$ & $1 / 2$ & $1 / 2$ & 1 & 7 & 7 & 3 & 3 & 5 & 1 & 5 & 5 & 0.044 & 7 \\
\hline $\begin{array}{l}\text { Cấu } \\
\text { trúc địa } \\
\text { động } \\
\text { lực }\end{array}$ & $1 / 8$ & $1 / 7$ & $1 / 6$ & $1 / 7$ & $1 / 7$ & 1 & 1 & 1 & 6 & 8 & 7 & 8 & 8 & 0.012 & 8 \\
\hline $\begin{array}{l}\text { Đới } \\
\text { ảnh } \\
\text { hưởng } \\
\text { động } \\
\text { lực các } \\
\text { đứt gãy } \\
\text { chính }\end{array}$ & $1 / 8$ & $1 / 7$ & $1 / 6$ & $1 / 7$ & $1 / 7$ & 1 & 1 & 1 & 6 & 8 & 7 & 8 & 8 & 0.012 & 8 \\
\hline $\begin{array}{l}\text { Gia tốc } \\
\text { nền }\end{array}$ & $1 / 4$ & $1 / 3$ & $1 / 3$ & $1 / 3$ & $1 / 3$ & 1 & 1 & 1 & 3 & 4 & 3 & 4 & 4 & 0.021 & 4 \\
\hline $\begin{array}{l}\text { Địa } \\
\text { chất } \\
\text { thủy } \\
\text { văn }\end{array}$ & $1 / 8$ & $1 / 7$ & $1 / 5$ & $1 / 3$ & $1 / 3$ & $1 / 6$ & $1 / 6$ & $1 / 3$ & 1 & 7 & 3 & 7 & 7 & 0.026 & 7 \\
\hline $\begin{array}{l}\text { Lượng } \\
\text { mưa } \\
\text { năm }\end{array}$ & $1 / 2$ & $1 / 3$ & $1 / 5$ & $1 / 5$ & $1 / 5$ & $1 / 8$ & $1 / 8$ & $1 / 4$ & $1 / 7$ & 1 & 5 & 1 & 1 & 0.148 & 5 \\
\hline $\begin{array}{l}\text { Hiện } \\
\text { trạng } \\
\text { sử dụng } \\
\text { dất }\end{array}$ & $1 / 6$ & $1 / 6$ & $1 / 2$ & 1 & 1 & $1 / 7$ & $1 / 7$ & $1 / 3$ & $1 / 3$ & $1 / 5$ & 1 & 5 & 5 & 0.044 & 5 \\
\hline $\begin{array}{l}\text { Mật độ } \\
\text { xây } \\
\text { dựng }\end{array}$ & $1 / 2$ & $1 / 3$ & $1 / 5$ & $1 / 5$ & $1 / 5$ & $1 / 8$ & $1 / 8$ & $1 / 4$ & $1 / 7$ & 1 & $1 / 5$ & 1 & 1 & 0.152 & 1 \\
\hline $\begin{array}{l}\text { Hệ } \\
\text { thống } \\
\text { giao } \\
\text { thông }\end{array}$ & $1 / 2$ & $1 / 3$ & $1 / 5$ & $1 / 5$ & $1 / 5$ & $1 / 8$ & $1 / 8$ & $1 / 4$ & $1 / 7$ & 1 & $1 / 5$ & 1 & 1 & 0.152 & 1 \\
\hline
\end{tabular}

Nguồn: Le và cộng sự (2020) 


\subsubsection{Các bản đồ thành phần}

Trượt lở đất do nhiều yếu tố tác động, nhưng thực tế không thể lúc nào cũng thu thập được các dữ liệu đầy đủ để xây dựng bản đồ phân vùng nguy cơ. Dựa trên việc nghiên cứu, đánh giá các yếu tố chủ yếu có khả năng gây ra trượt lở đất trên địa bàn Thành phố Đà Lạt, đã chọn ra 13 yếu tố/bản đồ thành phần với các phân lớp tương ứng (Bảng 2).

\section{Bảng 2}

Trọng số các phân lớp trong bản đồ thành phần

\begin{tabular}{|c|c|c|}
\hline Bản đồ thành phần & Phân lớp & $\begin{array}{l}\text { Trọng số } \\
\text { phân lớp } \\
(\mathbf{w})\end{array}$ \\
\hline \multirow{5}{*}{ Độ dốc sườn, phân làm năm lớp (Hình 4a) } & $<3^{\circ}$ & 0.006 \\
\hline & $3^{\circ}-8^{o}$ & 0.012 \\
\hline & $8^{\circ}-15^{\circ}$ & 0.024 \\
\hline & $15^{\circ}-25^{\circ}$ & 0.050 \\
\hline & $>25^{\circ}$ & 0.097 \\
\hline \multirow{5}{*}{$\begin{array}{l}\text { Địa mạo, gồm năm đơn vị địa mạo với } \\
\text { nguồn gốc nội sinh và ngoại sinh (Hình 4b) }\end{array}$} & Xâm thực - tích tụ và tích tụ & 0.003 \\
\hline & $\begin{array}{l}\text { Sườn vách kiến tạo bị bóc mòn gia } \\
\text { tốc }\end{array}$ & 0.006 \\
\hline & $\begin{array}{l}\text { Bề mặt lớp phủ bazan Neogen - } \\
\text { Đệ tứ bị phân cắt mạnh; Bề mặt } \\
\text { lớp phủ bazan Đệ tứ bị phân cắt } \\
\text { yếu }\end{array}$ & 0.120 \\
\hline & Sườn rửa trôi bóc mòn & 0.025 \\
\hline & $\begin{array}{l}\text { Sườn bóc mòn tổng hợp; Sườn } \\
\text { xâm thực - bóc mòn }\end{array}$ & 0.050 \\
\hline \multirow{5}{*}{$\begin{array}{l}\text { Luu vưc sông - Mật độ sông suối, gồm năm } \\
\text { lưu vực sông với mật độ sông suối khác } \\
\text { nhau (Hình 4c) }\end{array}$} & Đa Dung (Cam Ly) & 0.001 \\
\hline & Đa Nhim & 0.003 \\
\hline & Đa Nhim (phía Nam) & 0.005 \\
\hline & Đa Dung - Đơn Dương & 0.011 \\
\hline & Đa Dung (phía Bắc) & 0.021 \\
\hline \multirow{5}{*}{$\begin{array}{l}\text { Thạch hoc - vỏ phong hóa, có năm nhóm đá } \\
\text { chính, có nguồn gốc và thành phần khác } \\
\text { nhau dưới tác động của điều kiện kiến tạo } \\
\text { và quá trình phong hóa không đồng đều } \\
\text { (Hình } 4 \mathrm{~d} \text { ) }\end{array}$} & Đá trầm tích & 0.004 \\
\hline & Đá trầm tích bở rời Kainozoi & 0.010 \\
\hline & Đá phun trào axit - trung tính & 0.010 \\
\hline & Đá phun trào mafic & 0.010 \\
\hline & Đá xâm nhập axit - trung tính & 0.028 \\
\hline Thổ nhương, có năm nhóm đất chính với & Nhóm đất gley (sét - bột - cát) & 0.001 \\
\hline
\end{tabular}




\begin{tabular}{|c|c|c|}
\hline Bản đồ thành phần & Phân lớp & $\begin{array}{l}\text { Trọng số } \\
\text { phân lớp } \\
(\mathbf{w})\end{array}$ \\
\hline \multirow{4}{*}{$\begin{array}{l}\text { tầng dày đất khá sâu, độ dốc lớn dễ bị rửa } \\
\text { trôi và xói mòn, (Hình } 4 \mathrm{e} \text { ) }\end{array}$} & Nhóm đất phù sa (sét - bột cát) & 0.003 \\
\hline & $\begin{array}{l}\text { Nhóm đất phù sa đen (sét - bột - } \\
\text { cát) }\end{array}$ & 0.006 \\
\hline & Nhóm đất đỏ (sét - bột - cát) & 0.011 \\
\hline & Nhóm đất xám (cát - bột - sét) & 0.022 \\
\hline \multirow{2}{*}{$\begin{array}{l}\text { Cấu trúc địa động lục, tồn tại hai khối cấu } \\
\text { trúc địa động lực cấp } 03 \text { là Đà Lạt - Di } \\
\text { Linh và Đức Trọng (Hình 4f) }\end{array}$} & $\begin{array}{l}\text { Khối CTĐĐL cấp } 03 \text { Đà Lạt - Di } \\
\text { Linh }\end{array}$ & 0.006 \\
\hline & Khối CTĐĐL cấp 03 Đức Trọng & 0.006 \\
\hline \multirow{2}{*}{$\begin{array}{l}\text { Đới ảnh hưởng động lục các đưt gãy chính, } \\
\text { khu vực nghiên cứu chịu ảnh hưởng động } \\
\text { lực các đứt gãy của Đới thứ } 02 \text { (Đa Nhim - } \\
\text { Tánh Linh) về phía Đông (Hình } 4 \mathrm{~g} \text { ) }\end{array}$} & Không ảnh hưởng & 0.002 \\
\hline & $\begin{array}{l}\text { Chịu ảnh hưởng cùa Đới thứ } 02 \\
\text { (Đa Nhim - Tánh Linh) }\end{array}$ & 0.010 \\
\hline \multirow{3}{*}{$\begin{array}{l}\text { Gia tốc nền cưc đại (chu kỳ lặp lại } 10.000 \\
\text { năm) nằm trong khoảng 0.04-0.07g (Hình } \\
\text { 4h) }\end{array}$} & $0.04-0.05 g$ & 0.003 \\
\hline & $0.05-0.06 \mathrm{~g}$ & 0.005 \\
\hline & $0.06-0.07 \mathrm{~g}$ & 0.013 \\
\hline \multirow{5}{*}{$\begin{array}{l}\text { Địa chất thủy văn, có năm phức hệ chứa } \\
\text { nước (Hình } 4 \mathrm{i} \text { ) }\end{array}$} & Trầm tích Holocene & 0.001 \\
\hline & Hệ tầng Xuân Lộc & 0.002 \\
\hline & Hệ tầng Đơn Dương & 0.003 \\
\hline & Hệ tầng La Ngà & 0.007 \\
\hline & Hệ tầng Đèo Bảo Lộc & 0.013 \\
\hline \multirow{3}{*}{$\begin{array}{l}\text { Lượng mưa trung bình năm, gồm ba vùng } \\
\text { có lượng mưa trung bình năm khác nhau } \\
\text { (Hình } 4 \mathrm{j} \text { ) }\end{array}$} & $1600-1700 \mathrm{~mm}$ & 0.020 \\
\hline & $1700-1800 \mathrm{~mm}$ & 0.035 \\
\hline & $1800-1900 \mathrm{~mm}$ & 0.072 \\
\hline \multirow{5}{*}{$\begin{array}{l}\text { Hiện trạng sư dụng đất, gồm năm loại hình } \\
\text { sử dụng đất chính (Hình } 4 \mathrm{k} \text { ) }\end{array}$} & Đất trồng cây hằng năm khác; Lúa & 0.001 \\
\hline & Đất trồng rừng & 0.003 \\
\hline & Đất trồng cây lâu năm & 0.006 \\
\hline & Đất ở - dân cư & 0.011 \\
\hline & Đất phi nông nghiệp khác & 0.022 \\
\hline \multirow{4}{*}{$\begin{array}{l}\text { Mật độ xây dụng, đã sử dụng các ảnh viễn } \\
\text { thám do vệ tinh Sentinel-2A thu nhận ngày } \\
\text { 28/01/2019 từ website } \\
\text { https://earthexplorer.usgs.gov. Số hiệu ảnh: } \\
\text { S2A_MSIL1C_20190128T031001_ }\end{array}$} & $<20 \%$ & 0.005 \\
\hline & $20-40 \%$ & 0.010 \\
\hline & $40-60 \%$ & 0.020 \\
\hline & $60-80 \%$ & 0.040 \\
\hline
\end{tabular}




\begin{tabular}{|l|l|c|}
\hline \multicolumn{1}{|c|}{ Bản đồ thành phần } & \multicolumn{1}{|c|}{ Phân lớp } & $\begin{array}{c}\text { Trọng số } \\
\text { phân lớp } \\
\text { (w) }\end{array}$ \\
\hline \multirow{2}{*}{$\begin{array}{l}\text { N0207_R075_T48PZU_20190128T06070 } \\
\text { (Hình 4l) }\end{array}$} & $>80 \%$ & 0.078 \\
\hline \multirow{3}{*}{$\begin{array}{l}\text { Hệ thống giao thông, với các vùng đệm mồi } \\
\text { bên đường là 20m (Hình 4m) }\end{array}$} & $0-20 \mathrm{~m}$ & 0.078 \\
\cline { 2 - 3 } & $20-40 \mathrm{~m}$ & 0.040 \\
\cline { 2 - 3 } & $40-60 \mathrm{~m}$ & 0.020 \\
\cline { 2 - 3 } & $60-80 \mathrm{~m}$ & 0.010 \\
\cline { 2 - 3 } & $80-100 \mathrm{~m}$ & 0.005 \\
\hline
\end{tabular}

Nguồn: Le và cộng sự (2020)

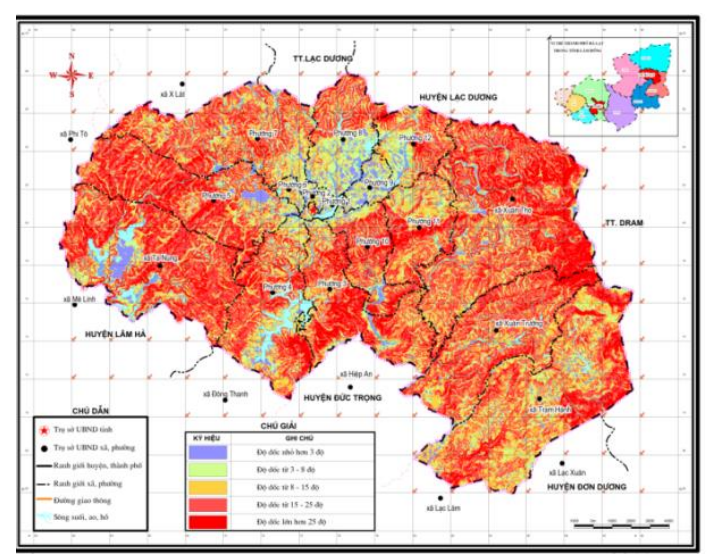

(a)

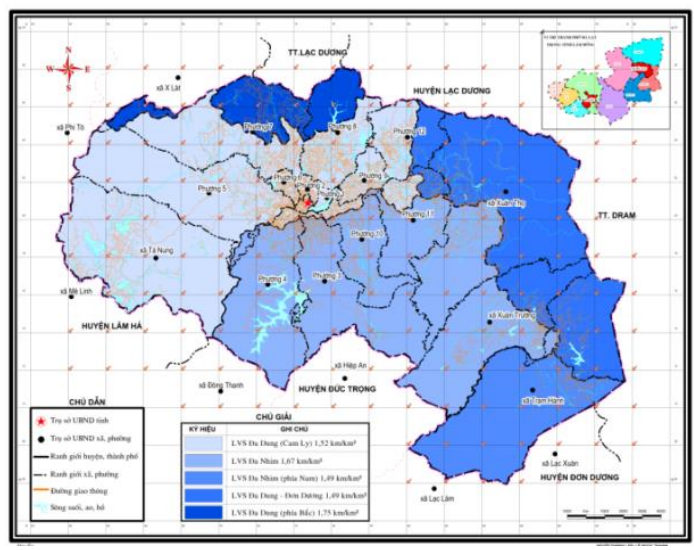

(c)

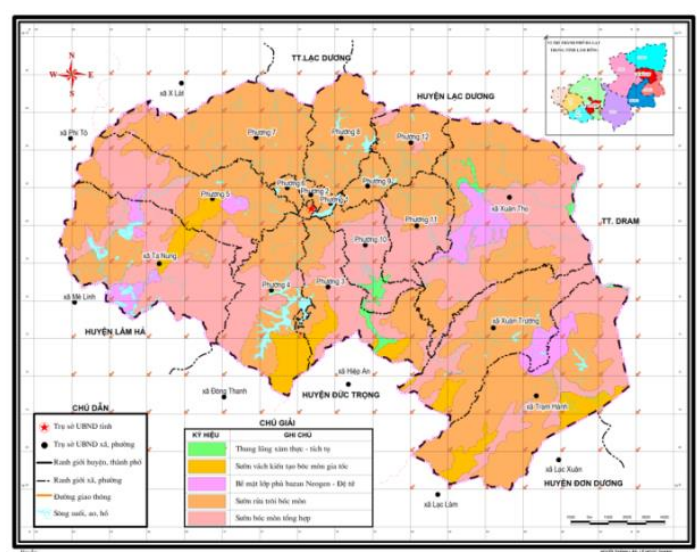

(b)

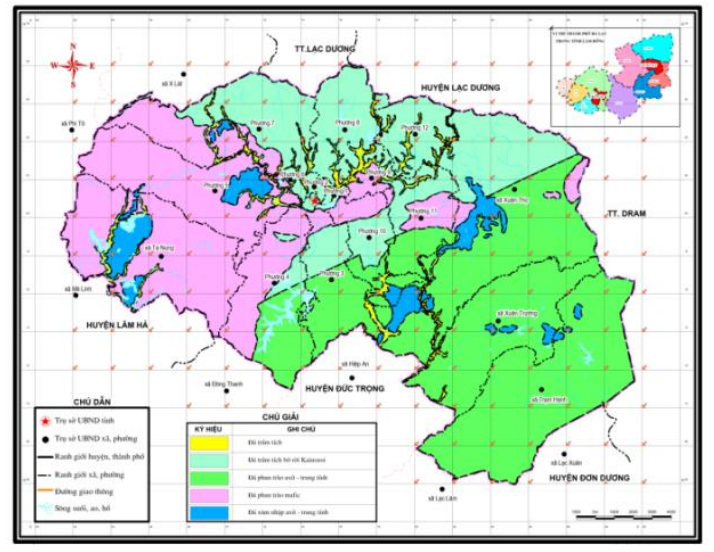

(d) 


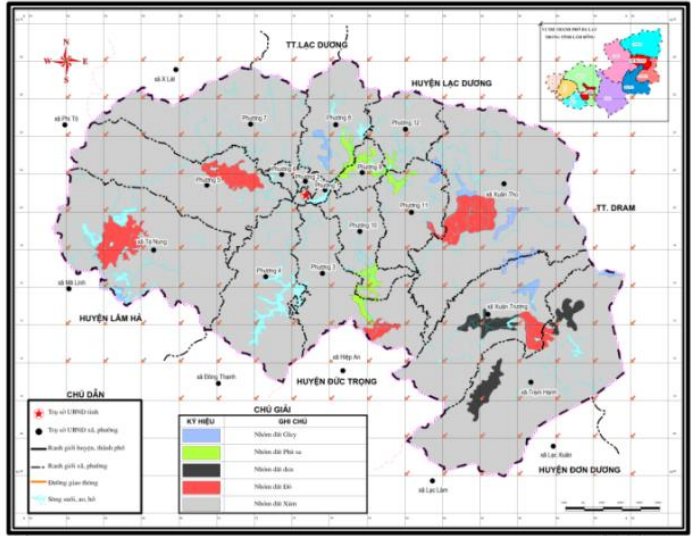

(e)

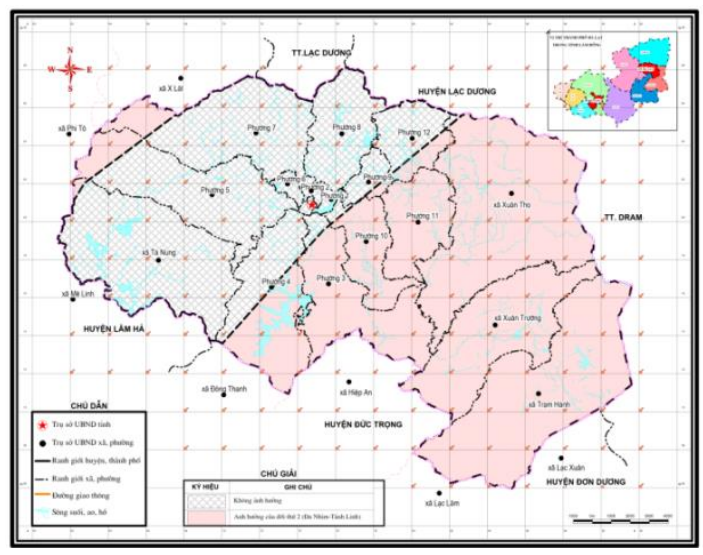

(g)

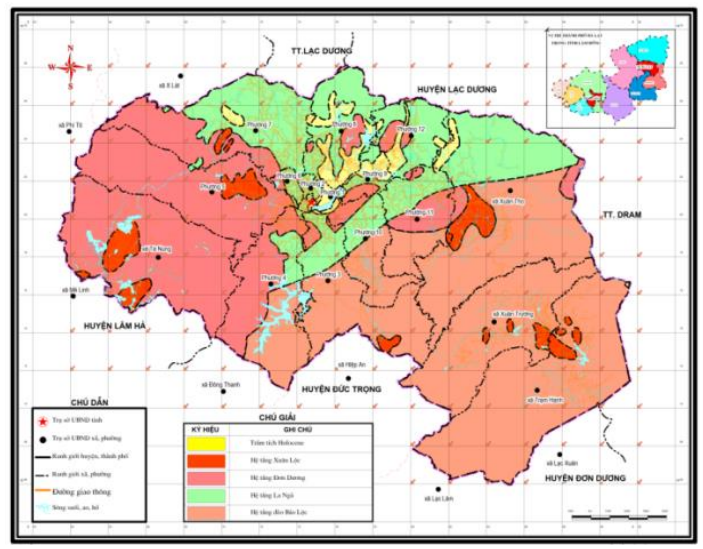

(i)

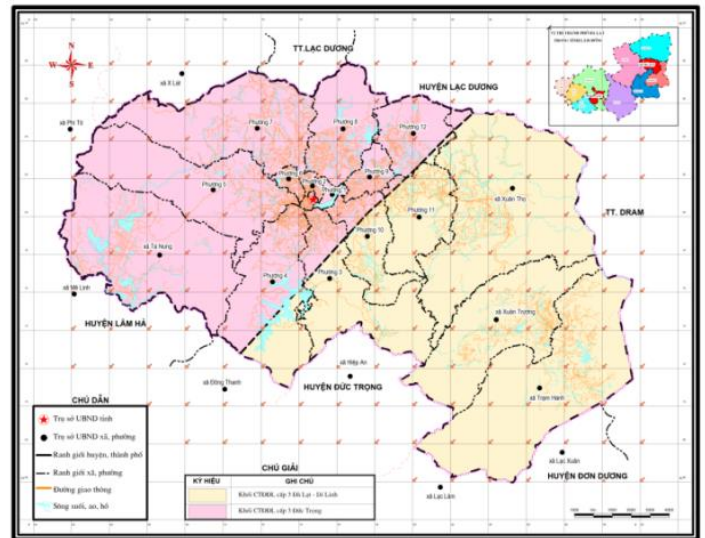

(f)

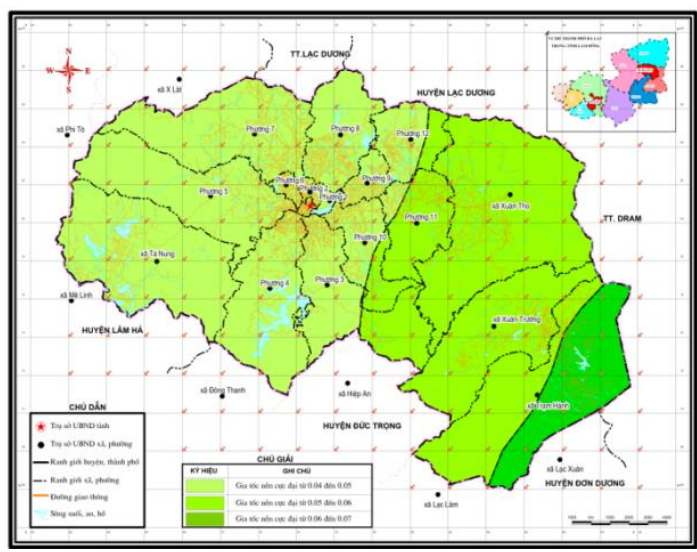

(h)

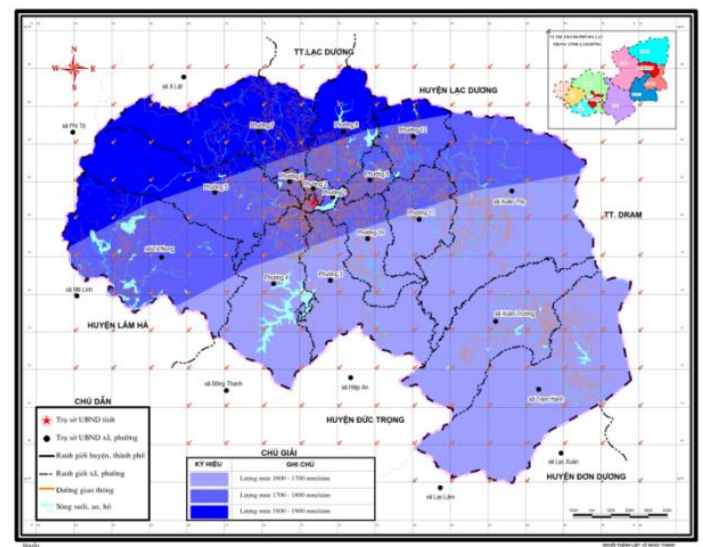

(j) 


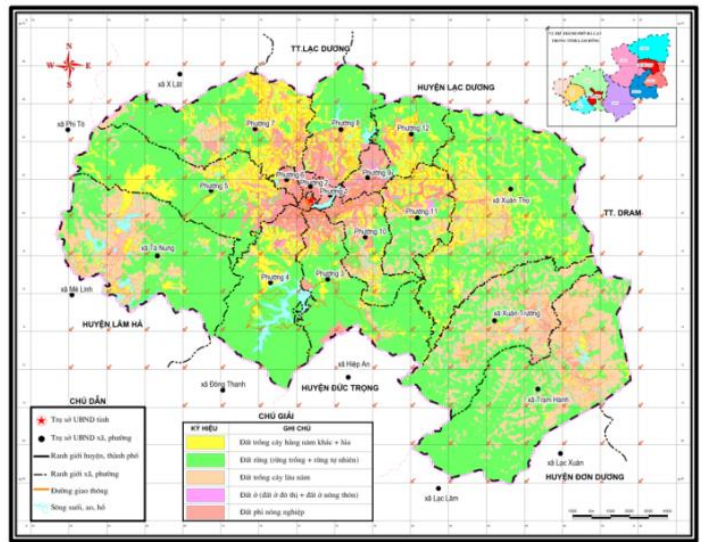

(k)

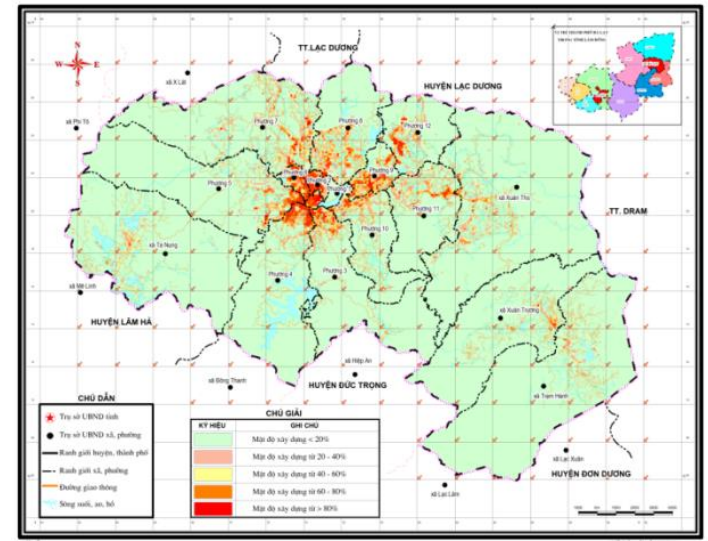

(1)

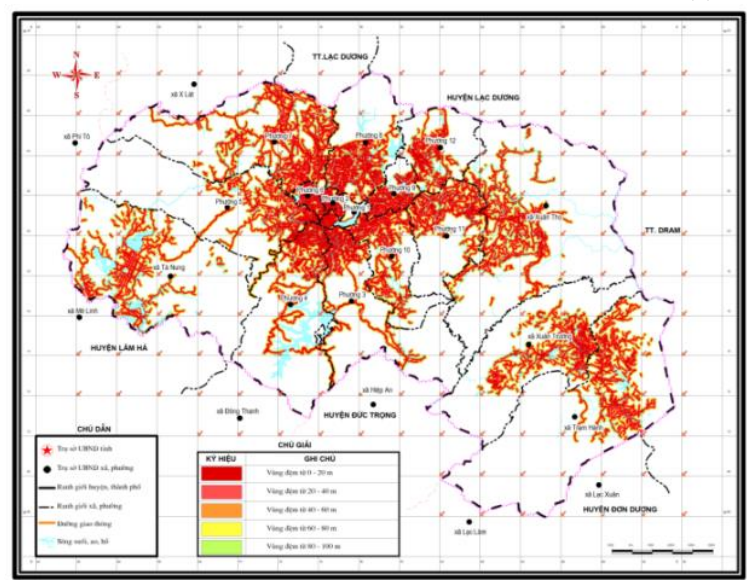

(m)

Hình 4. Bản đồ thành phần (a) Độ dốc sườn; (b) Địa mạo; (c) Lưu vực sông - mật độ sông suối; (d) Thạch học - vỏ phong hóa; (e) Thổ nhưỡng; (f) Cấu trúc địa động lực; (g) Đới ảnh hưởng động lực các đứt gãy chính; (h) Gia tốc nền cực đại; (i) Địa chất thủy văn; (j) Lượng mưa trung bình năm; (k) Hiện trạng sử dụng đất; (1) Mật độ xây dựng; (m) Hệ thống giao thông

\section{Kết quả và thảo luận}

\subsection{Phân tích thống kê hiện trạng truọt lở đất}

Trong khu vực nội thành, Phường 03 có số địa điểm trượt lở đất nhiều nhất, gồm 44 điểm chiếm tỉ lệ 20.56\%; Phường 01 không xảy hiện tượng tai biến địa chất nào; khu vực ngoại thành có các xã Tà Nung và Xuân Trường, mỗi xã xảy ra 09 tai biến địa chất, chiếm tỉ lệ $4.21 \%$. Trong nhóm đất nông nghiệp, trượt lở đất xảy ra tại 107 điểm, trong đó nhiều nhất trên đất rừng phòng hộ với 56 điểm, chiếm tỉ lệ $52.34 \%$; ít nhất trong đất bằng trồng cây lâu năm khác có hai địa điểm với tỉ lệ $1.87 \%$; trong nhóm đất phi nông nghiệp, trượt lở đất xảy ra tại 107 điểm, trong đó nhiều nhất trên đất giao thông với 66 điểm, chiếm tỉ lệ $61.68 \%$; ít nhất trong đất giáo dục và đất tôn giáo với tỉ lệ $0.93 \%$. Trượt lở đất là loại hình tai biến địa chất chiếm ưu thế so với các loại hình nứt, sụt đất, gồm 209 điểm với tỉ lệ $97.66 \%$, phân bố chủ yếu ở Phường 03 . Nứt đất là loại hình tai biến địa chất ít xảy ra nhất, chỉ có một điểm cũng ở Phường 03 . Các địa điểm trượt lở đất chủ yếu có nguyên nhân nhân sinh, chiếm tỉ lệ lớn, 94.86\%. Trong số 214 địa điểm trượt lở đất có 89 điểm chiếm tỉ lệ $41.59 \%$ không xác định quy mô do không thể tiếp cận khối trượt; trong số địa điểm còn lại có 75 điểm (35.05\%) có quy mô nhỏ; 29 điểm (13.55\%) có quy mô trung bình, và 20 điểm $(9.35 \%)$ có quy mô lớn. 
(Ghi chú: Rất lớn: > 10,000m³; Lớn: 1,000-10,000m³; Trung bình: $500-1,000 m^{3} ;$ Nhỏ: $<500 m^{3}$ ).

\subsection{Phân tích mối quan hệ không gian giữa các yếu tố/nguyên nhân và khả năng phát sinh truọt lở đất}

Quan hệ không gian giữa các yếu tố/nguyên nhân và khả năng phát sinh trượt lở đất được phân tích dựa trên kết quả trình bày trong Bảng 2 .

Độ dốc sườn là một trong các yếu tố đóng vai trò quan trọng nhất đối với trượt lở đất trong khu vực nghiên cứu. Trượt lở đất phát sinh với khả năng cao nhất ở các khu vực có độ dốc trên $25^{\circ}(\mathrm{w}=0.097)$, phân bố chủ yếu xung quanh trung tâm Thành phố Đà Lạt. Về địa mạo, đơn vị bề mặt lớp phủ bazan Neogen - Đệ tứ bị phân cắt mạnh; và bề mặt lớp phủ bazan Đệ tứ bị phân cắt yếu chiếm ưu thế trong phát sinh trượt lở đất $(\mathrm{w}=0.120)$. Điều này là do đây là địa hình thành tạo do nguồn gốc nội sinh. Các bề mặt này khá bằng phẳng, bề dày của các lớp phủ bazan này từ $05-50 \mathrm{~m}$. Bề mặt lớp phủ bazan bị phong hóa mạnh, tạo vỏ phong hóa dày $05-10 \mathrm{~m}$, có nơi lớp phủ bazan này bị phong hóa hoàn toàn. Đối với yếu tố lưu vực sông - mật độ sông suối, diện tích của chúng càng lớn thì khả năng thu lượng nước càng cao, tạo ra lưu lượng và tốc độ dòng chảy càng mạnh, dẫn đến khả năng lôi cuốn các vật liệu chân dốc làm phát sinh trượt lở đất. Trơng khu vực nghiên cứu lưu vực Đa Dung (phía Bắc) có khả năng cao phát sinh trượt lở đất $(\mathrm{w}=0.021)$ do nằm trong lưu vực sông Đa Dung với mật độ sông suối khá cao $\left(1.75 \mathrm{~km} / \mathrm{km}^{2}\right)$ của tỉnh Lâm Đồng. Nhóm đá xâm nhập axit - trung tính nhạy cảm nhất trong xuất hiện trượt lở đất $(\mathrm{w}=0.028)$, phù hợp với đánh giá từ mức độ mạnh đến rất mạnh đối với nhóm đá xâm nhập (Le và cộng sự, 2012; 2020). Nhóm đất xám (cát - bột - sét ) có trọng số lớn nhất $(\mathrm{w}=0.022)$ là do chúng có thành phần cấp hạt lớn nhất, dẫn đến khả năng phát sinh trượt lở đất cao nhất.

Kết quả tính toán các trọng số cho ba yếu tố cấu trúc địa động lực, đới ảnh hưởng động lực các đới đứt gãy chính và gia tốc nền cực đại cho thấy tác động của chúng không lớn $(\mathrm{w}=$ 0.006-0.013). Điều đó chứng tỏ hoạt động nội sinh tuy có vai trò quan trọng nhưng không quyết định trong phát sinh trượt lở đất. Trong yếu tố địa chất thủy văn, Hệ tầng Đèo Bảo Lộc có trọng số cao nhất $(\mathrm{w}=0.013)$, bề dày lớn, chất lượng nước tốt, nhưng nghèo nước, không có khả năng khai thác quy mô công nghiệp mà chỉ có ý nghĩa dân dụng phân tán ở vùng rìa Nam thành phố. Việc khai thác, sử dụng nước ngầm cho sản xuất nông nghiệp làm gia tăng nguy cơ phát sinh trượt lở đất trong khu vực tồn tại Hệ tầng này. Yếu tố lượng mưa đóng vai trò quan trọng trong quá trình và thời điểm phát sinh trượt lở đất. Lượng mưa trung bình nhiều năm thay đổi từ 18001900mm phân bố ở phía Tây Bắc thành phố là yếu tố quan trọng trong phát sinh trượt lở đất $(\mathrm{w}=$ 0.072), phù hợp với hiện trạng phần lớn địa điểm trượt lở đất xảy ra ở các Phường 07,05 và xã Tà Nung. Trong sử dụng đất, trọng số cao tập trung vào đất phi nông nghiệp khác $(\mathrm{w}=0.022)$. Điều này được giải thích là do sự gia tăng sản xuất nông nghiệp trong phát triển kinh tế thành phố.

Sự gia tăng dân số và phát triển kinh tế của thành phố khiến cho nhu cầu xây dựng công trình, nhà ở, ... ngày càng tăng, chiếm diện tích đất ngày càng lớn. Do đó gia tăng mật độ xây dựng là một trong các yếu tố/nguyên nhân của trượt lở đất. Khu vực có mật độ xây dựng trên $80 \%$ có khả năng cao nhất gây trượt lở đất $(\mathrm{w}=0.078)$ tập trung chủ yếu từ Phường 01 đến Phường 12. Trên địa bàn Thành phố Đà Lạt hệ thống giao thông ngày càng được hoàn thiện như các quốc lộ 20, 27C, ĐT 725..., do vậy phải sử dụng nhiều vật liệu, thay đổi địa hình - địa mạo cũng như cấu tạo địa chất nơi có công trình đi qua, dẫn đến nguy cơ xuất hiện trượt lở đất. Phạm vi chịu ảnh hưởng nhiều nhất $(\mathrm{w}=0.078)$ phát sinh trượt lở đất từ tâm đường ra hai bên $20 \mathrm{~m}$.

Trong số các phân lớp của 13 bản đồ thành phần (yếu tố) có thể nhận ra bốn phân lớp có trọng số cao với w thay đổi từ 0.072-0.097, chia làm hai nhóm: 
(i) Nhóm yếu tố tự nhiên: Độ dốc sườn $>25^{\circ}(\mathrm{w}=0.097)$ và lượng mưa trung bình năm từ $1800-1900 \mathrm{~mm}(\mathrm{w}=0.072)$, được coi là các yếu tố tĩnh, tiềm ẩn.

(ii) Nhóm yếu tố hoạt động nhân sinh: Mật độ xây dựng $>80 \%(\mathrm{w}=0.078)$ và hệ thống giao thông với bước đệm $20 \mathrm{~m}(\mathrm{w}=0.078)$, được coi là các yếu tố động, kích thích trực tiếp.

Có thể coi đây là bốn yếu tố/nguyên nhân chủ yếu trong phát sinh trượt lở đất trên địa bàn Thành phố Đà Lạt.

\subsection{Phân vùng nguy cơ truột lở đất}

Trọng số của 13 yếu tố/thành phần đã được xác định bằng phân tích $\mathrm{AHP}$ (Bảng 2). Bản đồ phân vùng nguy cơ trượt lở đất Thành phố Đà Lạt đã được thành lập (Hình 5 ) bằng cách sử dụng các trọng số $\mathrm{w}$ với phương pháp tổ hợp tuyến tính có trọng số bằng phần mềm ArcGIS. Giá trị pixel đối với các vùng trượt lở đất thay đổi từ rất thấp (0.06-0.17), thấp (0.17-0.21), trung bình (0.21-0.24), cao (0.24-0.29) đến rất cao (0.29-0.47). Các diện tích chứa giá trị pixel cao có khả năng xảy ra trượt lở đất cao hơn so với các giá trị pixel thấp. Việc phân loại các giá trị pixel này thực hiện bằng thuật toán Natural breaks.

Bản đồ phân vùng nguy cơ trượt lở đất cho thấy vùng có nguy cơ rất thấp chiếm $21.76 \%$ diện tích khu vực nghiên cứu, tập trung ở Phường 04 và xã Trạm Hành; vùng có nguy cơ thấp chiếm 36.14\% diện tích khu vực nghiên cứu, tập trung ở các xã Xuân Thọ, Xuân Trường, Trạm Hành và Tà Nung; vùng có nguy cơ trung bình chiếm $21.15 \%$ diện tích khu vực nghiên cứu, tập trung ở Phường 05 , các xã Xuận Thọ và Tà Nung; vùng có nguy cơ cao chiếm $15.91 \%$ diện tích khu vực nghiên cứu, tập trung ở các Phường $03,05,07,10$ và xã Xuân Thọ; và vùng có nguy cơ rất cao chiếm $5.04 \%$ diện tích khu vực nghiên cứu, tập trung ở các Phường 05,07 và các xã Xuân Thọ, Tà Nung.

\subsection{Kiểm chứng kết quả phân vùng nguy cơ truọt lở đất}

Để kiểm chứng bản đồ phân vùng dự báo nguy cơ trượt lở đất, 214 địa điểm trượt lở đất phát hiện đã được chồng chập lên bản đồ phân vùng nguy cơ trượt lở đất để đánh giá, kiểm chứng độ tin cậy của bản đồ. Kết quả là các địa điểm trượt lở đất nằm trong vùng nguy cơ rất cao chiếm tỉ lệ $48.8 \%$ với tần suất là 0.001326 , lớn nhất so với các vùng còn lại. Các vùng nguy cơ rất thấp, thấp, trung bình và cao có các tần suất lần lượt là $0.000051,0.0092,0.000469$ và 0.000799. Kết quả kiểm chứng toàn bộ chỉ ra 94.8\% địa điểm trượt lở đất xuất hiện trong các vùng nguy cơ từ trung bình đến rất cao (Hình 6). Điều đó cho thấy độ tin cậy có thể chấp nhận được của bản đồ phân vùng nguy cơ trượt lở đất Thành phố Đà Lạt. 


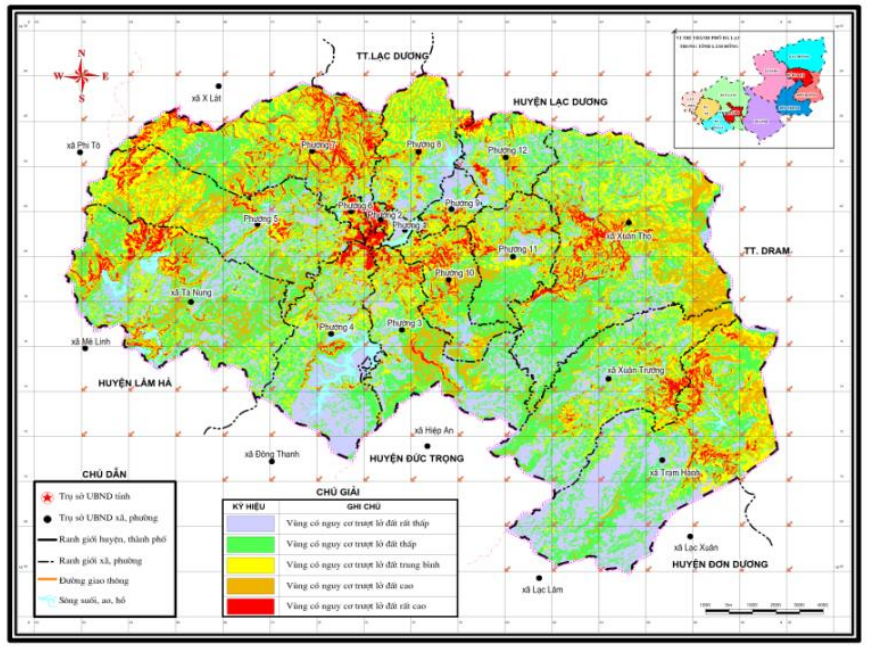

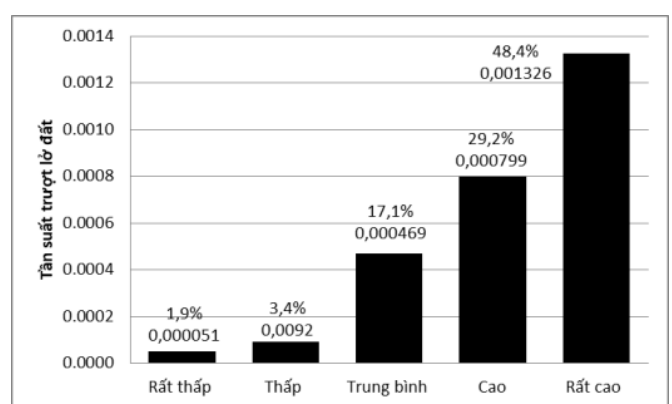

Hình 6. Tần suất trượt lở đất phát hiện trong các vùng nguy cơ

Hình 5. Bản đồ phân vùng nguy cơ trượt lở đất

Thành phố Đà Lạt

\section{Kết luận}

Bản đồ phân vùng nguy cơ trượt lở đất Thành phố Đà Lạt đã được thành lập qua sử dụng phương pháp phân tích thứ bậc AHP và công nghệ GIS, được kiểm chứng bằng cách so sánh với hiện trạng 214 địa điểm trượt lở đất đã phát hiện từ điều tra, khảo sát thực tế. Kết quả cho thấy $94.8 \%$ vị trí địa điểm trượt lở đất phát sinh trong các vùng nguy cơ từ trung bình đến rất cao. Các vùng có nguy cơ trượt lở đất từ rất thấp, thấp, trung bình, cao đến rất cao lần lượt chiếm $21.76 \%$; $36.14 \% ; 21.15 \% ; 15.91 \%$ và $5.04 \%$ diện tích khu vực nghiên cứu. Độ dốc sườn $>25^{\circ}$, lượng mưa trung bình năm từ $1800-1900 \mathrm{~mm}$, mật độ xây dựng $>80 \%$ và hệ thống giao thông với bước đệm $20 \mathrm{~m}$, được coi là các yếu tố/nguyên nhân chủ yếu trong phát sinh trượt lở đất trên địa bàn Thành phố Đà Lạt. Kết quả nghiên cứu là tài liệu khoa học và thực tiễn giúp các nhà quy hoạch và quản lý địa phương sử dụng hợp lý lãnh thổ thành phố có tính đến tai biến địa chất - trượt lở đất trong quy hoạch tổng thể phát triển kinh tế - xã hội.

\section{LÒ̀I CÁM ONN}

Bài báo này là một phần kết quả của đề tài "Nghiên cứu các tai biến địa chất: nứt, sụt đất, trượt lở đất và đề xuất các biện pháp cảnh báo, ngăn ngừa và khắc phục trên địa bàn Thành phố Đà Lạt, tỉnh Lâm Đồng." Các tác giả chân thành cám ơn Sở Khoa học và Công nghệ tỉnh Lâm Đồng đã hỗ trợ thực hiện đề tài và ý kiến của các phản biện để hoàn chỉnh bài báo.

\section{Tài liệu tham khảo}

Ahmad, A. (2018). Analytical Hierarchy (AHP) process method for environmental hazard mapping for Jeddah City, Saudi Arabia. Journal of Geoscience and Environment Protection, 6, 143-159.

Dang, Q. T., Nguyen, H. D., Indra, P., Abolfazl, J., Nguyen, V. T., Tran, V. P., \& Pham, T. B. (2019). GIS based frequency ratoi method for landslide susceptibility mapping at Da Lat City, Lam Dong province, Vietnam. Vietnam Journal of Earth Sciences, 42(1), 55-66, doi:10.15625/0866-7187/42/1/14758

Le, N. T., Nguyen, S. N., Nguyen, P. H., Luu, H. T., Nguyen, Q. D., Tran, A. H., \& Nguyen, T. T. 
K. (2020). Nghiên cưu các tai biến địa chất: Nứt, sụt đất, trượt lở đất và đề xuất các biện pháp cảnh báo, ngăn ngùa và khắc phục trên địa bàn thành phố Đà Lạt, tỉnh Lâm Đồng [Research on geological hazards: Cracking, landslide, landslide and propose measures to warn, prevent and overcome in Da Lat city, Lam Dong province]. Ho Chi Minh City, Vietnam: Viện Địa lý tài nguyên TP.HCM.

Le, N. T., Nguyen, S. N., Nguyen, V. D., Dang, H. V., Nguyen, Q. D., Dang, D. L., \& Do, L. V. (2012). Nghiên cúu tai biến địa chất nhũng vùng có nguy cơ nứt đất, truợt lở đất, lũ quét: Đề xuất các giải pháp phòng tránh, giảm nhe thiệt hại trên địa bàn tỉnh Lâm Đồng [Research on geological hazards in areas at risk of soil cracking, landslides and flash floods: Proposing solutions to prevent and mitigate damage in Lam Dong province]. Ho Chi Minh City, Vietnam: Viện Địa lý tài nguyên TP.HCM.

Nguyen, N. P., Kanno, T., \& Bui, V. T. (2017). Đánh giá nguyên nhân nứt nhà khu vực phường 2, thành phố Đà Lạt và đề xuất các giải pháp ổn định lâu dài [Assessing the causes of house cracking in ward 2, Da Lat city and proposing solutions for long-term stability]. Lam Dong, Vietnam: Sở Tài nguyên và Môi trường tỉnh Lâm Đồng.

Nguyen, X. H., Pham, V. H., Bui, V. T., Doan, D. L., Phan, D. P., Mai, T. T., . . Nguyen, M. Q. (2019). Tai biến địa chất khu vục Tây Nguyên [Geological disasters in the Central Highlands region]. Hanoi, Vietnam: Nhà xuất bản Khoa học tự nhiên và Công nghệ.

Ozdemir, A., \& Altural, T. (2013). A comparative study of frequencey ratio, weights of evidence and logistic regression methods fro landslide susceptibility mapping: Sultan Mountains, SW Turkey. Journal of Asian Earth Sciences, 64, 180-197. doi:10.1016/j.jseaes.2012.12.014

Peng, S.-H., Shieh, M.-J., \& Fan, S.-Y. (2012). Potential hazard map for disaster prevention using GIS-based linear combination approach and analytic hierarchy method. Journal of Geographic Information System, 4, 403-411. doi:10.4236/jgis.2012.45046

Pham, H. L., Do, V. L., \& Nguyen, X. B. (1994). Đứt gãy, trường úng suất kiến tạo tỉnh Lâm Đồng [Fault, tectonic stress field in Lam Dong province]. Ho Chi Minh City, Vietnam: Liên đoàn Bản đồ Địa chất Miền Nam.

Phan, T. T., Ngo, V. L., Nguyen, V. H., Tran, V. P., Bui, V. T., Nguyen, V. T., . . Tran, Q. H. (2016). Nghiên cúu hoạt động địa động lục hiện đại khu vục Tây Nguyên phục vu dụ báo các dạng tai biến địa chất ở các vùng đập, hồ chứa và đề xuất các giải pháp phòng tránh [Studying modern geodynamic activities in the Central Highlands for forecasting geological hazards in dams and reservoirs and proposing solutions to prevent them] (Mã số: TN3-T06 - Chương trình Tây Nguyên 3 [Code: TN3-T06 - Central Highlands Program 3]). Hanoi, Vietnam: Viện Địa Chất - Viện Hàn Lâm Khoa học và Công nghệ Việt Nam.

Rahim, I., Ali, S. M., \& Aslam, M. (2018). GIS based landslide susceptibility mapping with application of analytical hierarchy process in district Ghizer, Gilgit Baltistan Pakistan. Journal of Geoscience and Environment Protection, 6(2), 34-49.

Saaty, T. L. (1980). The analytical hierarchy process. New York, NY: McGraw Hill Press.

USGS. (n.d.). Earth explorer. Retrieved September 10, 2020, from https://earthexplorer.usgs.gov

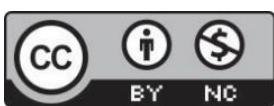

Creative Commons Attribution-NonCommercial 4.0 International License. 